\title{
Increased Cell Proliferation by Various Doses of Xenoestrogen in MFC-7 Cell Through Tyrosine Phosphatase Shp2
}

\author{
Wenjie Liu ${ }^{1, ~ *, ~ Q i n y u a n ~ W a n g ~}{ }^{1,2}$, Zhaokai Wang ${ }^{3}$, Defeng $\mathrm{Wu}^{2}$, Wenhua Liu ${ }^{4}$, Juan Wang ${ }^{4}$ \\ ${ }^{1}$ School of Pharmaceutical Sciences, Xiamen University, Xiamen, China \\ ${ }^{2}$ College of Animal Science, Fujian Agriculture and Forestry University, Fuzhou, China \\ ${ }^{3}$ Third Institute of Oceanography, State Oceanic Administration, Xiamen, China \\ ${ }^{4}$ Third People's Hospital of Pingdu, Pingdu, China
}

Email address:

wjliu@xmu.edu.cn (Wenjie Liu)

\section{To cite this article:}

Wenjie Liu, Qinyuan Wang, Zhaokai Wang, Defeng Wu, Wenhua Liu, Juan Wang. Increased Cell Proliferation by Various Doses of Xenoestrogen in MFC-7 Cell Through Tyrosine Phosphatase Shp2. American Journal of Bioscience and Bioengineering.

Vol. 3, No. 6, 2015, pp. 178-182. doi: 10.11648/j.bio.20150306.16

\begin{abstract}
Our previous study demonstrated that tyrosine phosphatase Shp2 mediates the estrogen biological action in breast cancer. However, consumer research suggests that the Xenoestrogens exposure in breast tumorigenesisis more important. The present study examined the consequences of different concentrations xenoestrogens exposure to Bisphenol A (BPA) and Nonyl Phenol (NP) on cell proliferation and shp2 expression in MCF-7 cell. Phps1 $\left(2 \times 10^{-8} \mathrm{M}\right)$, BPA $\left(10^{-12}, 10^{-11}, 10^{-10}, 10^{-9}, 10^{-8}, 10^{-7}\right.$, $\left.10^{-6} \mathrm{M}\right), \mathrm{N} P\left(10^{-12}, 10^{-11}, 10^{-10}, 10^{-9}, 10^{-8}, 10^{-7}, 10^{-6} \mathrm{M}\right)$ and was administered in MCF-7 cell, respectively. Results showed the exposure of various concentrations xenoestrogens significantly elevated cell proliferation $(\mathrm{P}<0.05)$. Proliferation of MCF-7 cells was down regulated by Phps1 (a Shp2 inhibitor) when cells were treated for $1 \mathrm{~h}$. In addition, the tyrosine phosphatase Shp2 levels were higher in BPA- and NP-exposed indicating that Shp2 plays a crutial role for Xenoestrogens exposure facilitating breast tumorigenesis properties.
\end{abstract}

Keywords: Xenoestrogens, Cellproliferation, Shp2, MCF-7 Cell

\section{Introduction}

Bisphenol A (BPA) is the principal constituent of bottles, metal cans, and plastic food containers. BPA was firstly discovered in 1891 and tested as an artificial estrogen by Charles Dodds in the early 1930s. The occurrence of estrogen-like activity of the xenoestrogen BPA has been recently demonstrated both in environmental and human samples [1]. Previous reports suggest that BPA exposure may stimulate breast cancer progression in vitro $[2,3]$ and animal studies such as in mice [4], rats [5] and rhesus monkeys [6, 7]. The synthetic Nonylphenol (NP) has been widely used in manufacturing antioxidants, lubricating oil additives, laundry and dish detergents, emulsifiers, and solubilizers. NP was found that it may interfere with the progress in breast cancer $[3,8]$, ovarian cancer $[9,10]$. In recent years, BPA and NP extensively are widely found in the environment for its widespread application. BPA and NPare considered weak environmental estrogen, have been shown to stimulate the proliferation of human breast cancer cells, which may induce multiple biological responses and have the ability to influence breast cancer metastasis via through regulating a variety of signaling pathways. However, the underlying mechanism has not been fully elucidated.

Statistics from World Health Organization show breast cancer is the leading type of cancer in women in the worldwide, accounting for $25 \%$ of all cases by World Cancer Report in 2014. Previous research show that sex hormones are required for growth and development effects of the reproductive systems and the non-reproductive, and are involved in the biological action of the mammary gland elicited by estrogens and estrogen receptors (ERs) [11, 12]. A large quantity of endocrine-disrupting chemicals (EDCs) exert estrogen-like activity and disrupt normal physiological functions regulated by estrogen which can be classified as xenoestrogens, and the xenoestrogens can interfere with estrogen sensitivity and have adverse effects on hormonal and 
homeostatic systems. Many Xenoestrogens, including BPA and NP, have been traditionally considered to interact with the classical estrogen receptors (ERalpha and ERbeta) [13, 14] and the G protein-coupled receptor (GPR30/GPER) [15, 16], the nuclear receptors that functions as the master regulator of xenoestrogens regulation. However, while many of whom have not realized that non-nuclear receptor pathways could also mediate cell proliferation signaling until the discovery of tyrosine phosphatase Shp2, a novel membrane receptor, which can enter into the nucleus and play a significant role in endonuclear and extranuclear.

Tyrosine phosphatase Shp2 is a SH2-containing a ubiquitously expressed tyrosine-specific protein phosphatase [17]. Shp2 participates in signaling events downstream of receptors for growth factors, cytokines, hormones, antigens and extracellular matrices in the control of cell growth, differentiation, migration, and death. Activation of Shp2 and its association with Gabl is critical for sustained Erk activation downstream of several growth factor receptors and cytokines. Our previous research results strongly suggest that tyrosine phosphatase Shp2 mediates the estrogen biological action in breast cancer via Interaction with the estrogen extranuclear receptor. How the Xenoestrogens disrupt endocrine is unclear. In addition, we wanted to establish that BPA and NP, the potential EDCs, may have the ability to influence breast cancer progression via regulating Shp2 and proliferation in breast cancer cells.

\section{Materials and Methods}

\subsection{Cell Culture and Treatment}

Human MCF7 breast cancer cell line was purchased from the Chinese Academy of Sciences (Shanghai, China). The cells were incubated in Dulbecco's modified Eagle's medium (DMEM, Hyclone, USA) supplemented with 10\% (vol/vol) heat-inactivated fetal calf serum (FBS), $100 \mathrm{IU} / \mathrm{mL}$ penicillinand $100 \mathrm{mg} / \mathrm{mL}$ streptomycin. To determine the effects of Xenoestrogens in the media, the cells were pretreated for at least 6 days with an phenol red-free DMEM supplemented with $10 \%$ charcoal dextran-stripped FBS prior to experimental treatment.

Phps1 (P0039, Sigma) was dissolved in PBS solution. BPA (239658, Sigma) and NP (74430, Sigma) were dissolved in DMSO. The MCF7 cell were pretreated with the Phps1 (a specific inhibitor of Shp2 activity) for $12 \mathrm{~h}$ on $7.5 \mathrm{~d}$. Then these compounds BPA and NP were added to the medium during $8 \mathrm{~d}$ for MTT assay or Western blot each time.

Total cellular protein was extracted with RIPA buffer at 24 $\mathrm{h}$ after the treatment with chemicals of BPA or NP. The cellularprotein samples were stored at $-80^{\circ} \mathrm{C}$ until assaying for phosphatase protein Shp2.

\subsection{Cell Proliferation Assay}

MCF cell proliferation was measured using the MTT assay. The cells were seeded at a density of $3 \times 10^{3}$ cells/well in 96-well microtitre plates. The MCF7 cells were pretreated with the Shp2 inhibitor Phps1 for $12 \mathrm{~h}$ on $7.5 \mathrm{~d}$. Then the MCF-7 cells were treated with $\operatorname{DMSO}(0.1 \%)$, BPA $\left(10^{-12}\right.$, $\left.10^{-11}, 10^{-10}, 10^{-9}, 10^{-8}, 10^{-7}, 10^{-6} \mathrm{M}\right)$ or NP $\left(10^{-12}, 10^{-11}, 10^{-10}\right.$, $10^{-9}, 10^{-8}, 10^{-7}, 10^{-6} \mathrm{M}$ ) in the medium described above for 8 din 96 -well plates for 48 h. $200 \mu \mathrm{l}$ per well of cell suspension were co-incubated with $10 \mu 1$ of 3-(4,5-dimethylthiazol-2-yl)-2,5-diphenyltetrazolium (MTT) solution $(5 \mathrm{mg} \mathrm{MTT} / \mathrm{ml})$ at $37^{\circ} \mathrm{C}$ in a $5 \% \mathrm{CO}_{2}$ incubator for another $4 \mathrm{~h}$. The plates were measured at $560 \mathrm{~nm}$ using a Multiscan plate reader (MK3, Thermo).

\subsection{Western Blot Analysis}

Briefly, the protein samples were separated by $10 \%$ SDS-PAGE gel, heated, and then electrotransferred onto nitrocellulose membranes. The membranes were blocked for 2 $\mathrm{h}$ with 5\% BSA in phosphate-buffered saline (PBS) containing Tween-20 (PBST). The membranes were immunostained with primary antibodies for Shp2 (Santa Cruz Biotechnology, Inc.) overnight at $4{ }^{\circ} \mathrm{C}$. And then were incubated with horse anti-mouse IgG secondary antibodies at room temperature for $1 \mathrm{hr}$. Immunoreactivity was detected by the Western blotting detection kitof ECL (K-12045-D50, Westernbright, advansta, CA, USA).

\subsection{Statistics}

Data were analyzed by one-way ANOVA using of SPSS 15.0 (SPSS Inc., Chicago, IL, USA). Results were evaluated by as the mean $\pm \mathrm{SD}$. Statistical significance was accepted at $\mathrm{P}$ $<0.05$.

\section{Results}

\subsection{Effect of Shp2 Inhibitors Phps1on BPA and NP-Induced Cell Proliferation of MCF7 Cell}

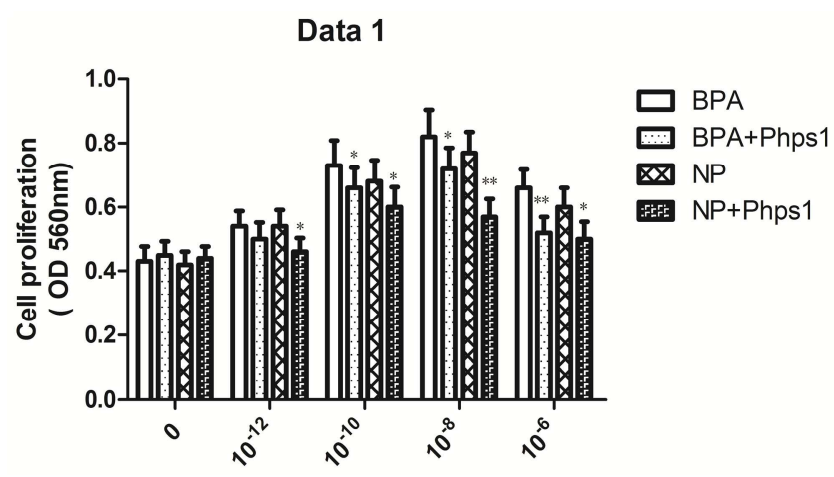

Fig. 1. Histograms demonstrating changes in MCF7 cell proliferation under various concerations of BPA, BPA+Phps1, NP and NP +Phps1. The cell proliferation continually increased from $10^{-12}$ to $10^{-8}$, and then declined with Phps 1 treatment.

To evaluate the MCF7human breast cancer cell growth, MTT assay for cell proliferation was used. The proliferation ability of MCF7 cells increased from $10^{-12}$ to $10^{-8} \mathrm{M}$ (BPA:44\%, NP:30\%), and then decreased in $10^{-6} \mathrm{M}$ in all BPA and NP -treatment groups ( $p<0.05$, Fig. 1$)$. However, between $10^{-8}$ and $10^{-6} \mathrm{M}$ of BPA -treatment group, it was 
relatively lower in pretreated with the Shp2 inhibitors phps1(up to $26 \%$ and $27 \%$, respectively), whereas in NP -treatment group the cell proliferation was lower in pretreated with the phps 1 from $10^{-8}$ to $10^{-6} \mathrm{M}$ than in the control groups ( $35 \%$ and $20 \%$, respectively). In contrast, no significant differences were observed at $0 \mathrm{M}$ (control group) or $10^{-12} \mathrm{M}$ in pretreated with Phpslin NP -treatment group $(\mathrm{p}>0.05)$.

These data indicated the Shp2 inhibitor Phps1 was involved in the down regulation of BPA- and NP-induced changes of proliferation in MCF7 cell.

\subsection{Changes in Shp2-Expressing in MCF7 Celltreated with Xenoestrogens of BPA and NP}

Tyrosine phosphatase Shp2levels in MCF7cell under BPA and NP treatment were shown in Fig. 2. The Shp2levels were higher in BPA and NP groups from $10^{-12}$ to $10^{-7} \mathrm{M}$ than the control group, respectively. However, no significant difference was observed in NP group of $10^{-6} \mathrm{M}$ treatment $(\mathrm{p}>$ 0.05). These finding indicated that BPA and NP could enhance expression of tyrosine phosphatase Shp2inMCF7cell.

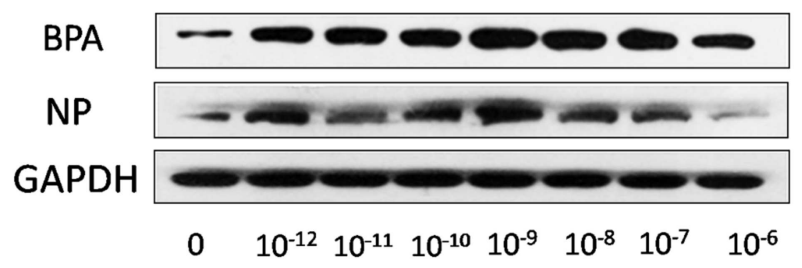

Fig. 2. Characterization of the Shp2expression, as quantified by western blot, under the various concerations exposure to BPA and NP.

The current study analyzed whether exposure to various doses of BPA or NP in MFC7 cell alters cell proliferation and tyrosine phosphatase Shp2 expression. Our results show that xenoestrogen exposure Increased cell proliferation, affecting Shp2 expression.

\section{Discussion}

It is generally accepted estrogen is responsible for normal reproductive development and fertility, while accumulated exposure to estrogen is a high risk factor in tumorigenesis of the estrogen-dependent organs. EDCs having similar structures to estrogen and may exertestrogen-like activity by interacting with the classical estrogen receptors (ERalpha and ERbeta) $[14,18]$ or through the $G$ protein-coupled receptor (GPR30/GPER) [15, 16], which is suspected to promote carcinogenesis by interfering with hormone balance and estrogen signaling $[10,15,19]$. The previous studies actually have proven these concerns. They are able to exert adverse effects through various mechanisms of action. Moreover, an increasing number of reports show that steady exposure to EDCs may also enhance the risk of cancers [20, 21]. BPA and NP are typical EDCs, which are monomers used to a high extent in our life [22]. Experimental laboratory evidence suggests that BPA is harmful to humans, especially relevant to cancers, which is anintense topic of debate $[23,24]$. BPA exposure is established the contribution to adverse effects associated prostate cancer [25], breast cancer and ovarian cancer $[10,19]$. It was reported that NP could accelerate cell growth by regulating cell cycle-related genes [26].

It has been well documented that estrogen is a pacesetter of human breast cancer development, and Xestrogens such as BPA and NP are currently under heated argument. This indicates that BPA and NP may stimulate cancer cell growth by a different mechanism. Recently, a new estrogen membrane receptor Shp2 was identified. Tyrosine phosphatase Shp2 has latterly been shown to play a critical role in estrogen signalling and functions in breast cancer development [27-30]. It was also found that Shp2 appears to regulate the Ras-MAPK、PKB/AKT pathway while affecting extracellular-regulated kinase activation by estrogen $[29,30]$, which can bind to the estrogen receptor and IGF-1 membrane receptor, mediated the regulation of estrogen membrane receptor signaling in breast cancer.

Our previous studies suggested that tyrosine phosphatase Shp2 mediates the estrogen biological action in breast cancer [29]. Therefore, in present study, we made further investigation into Xenoestrogen exposure in proliferative activity in MCF7 cells by both MTT assay (cell proliferative activity) and western blot (tyrosine phosphatase Shp2 level). Estrogen-like activity is attributed to EDCs, such as BPA or NP, has been recently demonstrated both in environmental and human samples, but mechanisms of action and diversity of effects are poorly understood. In this study, we used in vitro models to evaluate the actions of BPA, and NP on Shp2 expression. We found that BPA and NP had estrogenic activity and activated functions of Shp2. In addition, both compounds induced the action-mediated response for cell proliferation.

\section{Conclusion}

In summary, our results show that exposure to various doses of BPA and NP increase cell proliferation of MCF7 cell and alter tyrosine phosphatase Shp2 expression. These findings emphasize and indicate the involvement of Shp2 in the initiation and development of a variety of breast cancer exposure to BPA and NP.

\section{Acknowledgements}

This work was supported by the Natural Science Foundation of Fujian Province of China (No.2012J01155); the Fundamental Research Funds for the Central Universities.

\section{References}

[1] Soto AM, Vandenberg LN, Maffini MV, Sonnenschein C: Does breast cancer start in the womb? Basic Clin Pharmacol 2008, 102(2): 125-133. 
[2] Pupo M, Pisano A, Lappano R, Santolla MF, De Francesco EM, Abonante S, Rosano C, Maggiolini M: Bisphenol A induces gene expression changes and proliferative effects through GPER in breast cancer cells and cancer-associated fibroblasts. Environ Health Perspect 2012, 120(8): 1177-1182.

[3] Zhang W, Fang Y, Shi X, Zhang M, Wang X, Tan Y: Effect of bisphenol A on the EGFR-STAT3 pathway in MCF-7 breast cancer cells. Molecular medicine reports 2012, 5(1): 41-47.

[4] Jenkins S, Wang J, Eltoum I, Desmond R, Lamartiniere CA: Chronic oral exposure to bisphenol A results in a nonmonotonic dose response in mammary carcinogenesis and metastasis in MMTV-erbB2 mice. Environ Health Perspect 2011, 119(11): 1604-1609.

[5] Jenkins S, Raghuraman N, Eltoum I, Carpenter M, Russo J, Lamartiniere CA: Oral exposure to bisphenol a increases dimethylbenzanthracene-induced mammary cancer in rats. Environ Health Perspect 2009, 117(6): 910-915.

[6] Tharp AP, Maffini MV, Hunt PA, VandeVoort CA, Sonnenschein C, Soto AM: Bisphenol A alters the development of the rhesus monkey mammary gland. Proceedings of the National Academy of Sciences of the United States of America 2012, 109(21): 8190-8195.

[7] Hunt PA, Lawson C, Gieske M, Murdoch B, Smith H, Marre A, Hassold T, VandeVoort CA: Bisphenol A alters early oogenesis and follicle formation in the fetal ovary of the rhesus monkey. Proceedings of the National Academy of Sciences of the United States of America 2012, 109(43): 17525-17530.

[8] Chen CL, Chiang TH, Tseng PC, Wang YC, Lin CF: Loss of PTEN causes SHP2 activation, making lung cancer cells unresponsive to IFN-gamma. Biochem Biophys Res Commun 2015, 466(3): 578-584.

[9] Park MA, Hwang KA, Lee HR, Yi BR, Choi KC: Cell Growth of BG-1 Ovarian Cancer Cells was Promoted by 4-Tert-octylphenol and 4-Nonylphenol via Downregulation of TGF-beta Receptor 2 and Upregulation of c-myc. Toxicological research 2011, 27(4): 253-259.

[10] Kim YS, Hwang KA, Hyun SH, Nam KH, Lee CK, Choi KC: Bisphenol A and nonylphenol have the potential to stimulate the migration of ovarian cancer cells by inducing epithelial-mesenchymal transition via an estrogen receptor dependent pathway. Chemical research in toxicology 2015, 28(4): 662-671.

[11] Pessina MA, Hoyt RF, Jr., Goldstein I, Traish AM: Differential regulation of the expression of estrogen, progesterone, and androgen receptors by sex steroid hormones in the vagina: immunohistochemical studies. J Sex Med 2006, 3(5): 804-814.

[12] Piatkowski K, Kruk-Zagajewska A, Thielemann A, Kopczynski Z: [Correlation of sex hormones in blood serum and estrogen-progesterone receptors concentration in patients with laryngeal cancer]. Otolaryngol Pol 2002, 56(6): 675-681.

[13] Vivacqua A, Recchia AG, Fasanella G, Gabriele S, Carpino A, Rago V, Di Gioia ML, Leggio A, Bonofiglio D, Liguori A et al: The food contaminants bisphenol A and 4-nonylphenol act as agonists for estrogen receptor alpha in MCF7 breast cancer cells. Endocrine 2003, 22(3): 275-284.

[14] Shen H, Xu P, Yu W, Liu Y, Wu D: [Effects of p-nonylphenol on expression of ER protein and ER alpha mRNA of MCF-7 cells]. Sichuan da xue xue bao Yi xue ban = Journal of Sichuan University Medical science edition 2003, 34(4): 641-644.
[15] Ge LC, Chen ZJ, Liu HY, Zhang KS, Liu H, Huang HB, Zhang $\mathrm{G}$, Wong CK, Giesy JP, Du J et al: Involvement of activating ERK1/2 through $G$ protein coupled receptor 30 and estrogen receptor alpha/beta in low doses of bisphenol A promoting growth of Sertoli TM4 cells. Toxicol Lett 2014, 226(1): 81-89.

[16] Dong S, Terasaka S, Kiyama R: Bisphenol A induces a rapid activation of Erk1/2 through GPR30 in human breast cancer cells. Environ Pollut 2011, 159(1): 212-218.

[17] Dance M, Montagner A, Salles JP, Yart A, Raynal P: The molecular functions of Shp2 in the Ras/Mitogen-activated protein kinase (ERK1/2) pathway. Cell Signal 2008, 20(3): 453-459.

[18] Burns KA, Li Y, Arao Y, Petrovich RM, Korach KS: Selective mutations in estrogen receptor alpha D-domain alters nuclear translocation and non-estrogen response element gene regulatory mechanisms. The Journal of biological chemistry 2011, 286(14): 12640-12649.

[19] Park MA, Choi KC: Effects of 4-nonylphenol and bisphenol A on stimulation of cell growth via disruption of the transforming growth factor-beta signaling pathway in ovarian cancer models. Chemical research in toxicology 2014, 27(1): 119-128.

[20] Prins GS, Tang WY, Belmonte J, Ho SM: Developmental exposure to bisphenol A increases prostate cancer susceptibility in adult rats: epigenetic mode of action is implicated. Fertil Steril 2008, 89(2 Suppl): e41.

[21] Yi BR, Jeung EB, Choi KC: 204 altered gene expression following exposure to bisphenol a in human ovarian cancer cells expressing estrogen receptors by microarray. Reprod Fertil Dev 2011, 23(1): 201.

[22] Schafer TE, Lapp CA, Hanes CM, Lewis JB, Wataha JC, Schuster GS: Estrogenicity of bisphenol A and bisphenol A dimethacrylate in vitro. J Biomed Mater Res 1999, 45(3): 192-197.

[23] Murray TJ, Maffini MV, Ucci AA, Sonnenschein C, Soto AM: Induction of mammary gland ductal hyperplasias and carcinoma in situ following fetal bisphenol A exposure. Reprod Toxicol 2007, 23(3): 383-390.

[24] Richter CA, Birnbaum LS, Farabollini F, Newbold RR, Rubin BS, Talsness CE, Vandenbergh JG, Walser-Kuntz DR, vom Saal FS: In vivo effects of bisphenol A in laboratory rodent studies. Reprod Toxicol 2007, 24(2): 199-224.

[25] Hess-Wilson JK, Webb SL, Daly HK, Leung YK, Boldison J, Comstock CE, Sartor MA, Ho SM, Knudsen KE: Unique bisphenol A transcriptome in prostate cancer: novel effects on ERbeta expression that correspond to androgen receptor mutation status. Environ Health Perspect 2007, 115(11): 1646-1653.

[26] Boonyaratanakornkit V, Edwards DP: Receptor mechanisms mediating non-genomic actions of sex steroids. Semin Reprod Med 2007, 25(3): 139-153.

[27] Zhang J, Zhang F, Niu R: Functions of Shp2 in cancer. J Cell Mol Med 2015, 19(9): 2075-2083.

[28] Serrano M: SHP2: a new target for pro-senescence cancer therapies. EMBO J 2015, 34(11): 1439-1441.

[29] Li J, Kang Y, Wei L, Liu W, Tian Y, Chen B, Lin X, Li Y, Feng GS, Lu Z: Tyrosine phosphatase Shp2 mediates the estrogen biological action in breast cancer via interaction with the estrogen extranuclear receptor. PLoS One 2014, 9(7): e102847. 
[30] He Z, Zhang SS, Meng Q, Li S, Zhu HH, Raquil MA, Alderson $\mathrm{N}$, Zhang H, Wu J, Rui L et al: Shp2 controls female body weight and energy balance by integrating leptin and estrogen signals. Mol Cell Biol 2012, 32(10): 1867-1878. 